\title{
ESPACIO SOCIAL TRANSNACIONALY DESARROLLO: UNA EXPLORACIÓN DE LA RELACIÓN ENTRE COMUNIDAD, ESTADO Y MERCADO

\author{
THOMAS FAIST*
}

\author{
Traducción del inglés \\ Luis Rodolfo Morán
}

\begin{abstract}
ResUmen. Este trabajo aborda el vínculo que establecen grupos y asociaciones transnacionales con el Estado y el mercado mediante los envíos de dinero, conocimiento e ideas que hacen los migrantes a sus países de origen. Bajo lo que se denomina globalización, reflexiona acerca de los cambios ocurridos en la relación entre comunidad, Estado y mercado. Adicionalmente, cuestiona żcómo el diseño de políticas de "desarrollo» y el trabajo académico han moldeado el papel de las formaciones sociales transnacionales y de las organizaciones no estatales?, żde qué manera la actividad de las cámaras, grupos y organizaciones transnacionales, que encarnan principios comunitarios, resultan complementarias o incompatibles con las de otras instituciones que funcionan según la lógica estatal y mercantil?

Palabras ClaVE. Transnacionalismo, desarrollo, comunidad, mercado, Estado.
\end{abstract}

ABSTRACT. This study deals with the link established by transnational groups and associations with the state and market by the sending of money, knowledge and ideas by migrants to their countries of origin. Under the rubris of 'globalization' it reflects on the changes that have occured in the relations among community, state and market. It also questions the way that the design of «development» policies and academic work in this area have shaped the role of transnational social formations and non-state organizations.

KeYWORDS. Transnationalism, development, community, market, state.

"Centro de Estudios de la Migración, la Ciudadanía y el Desarrollo, Facultad de Sociología de la Universidad de Bielefeld, Alemania. 


\section{INTRODUCCIÓN}

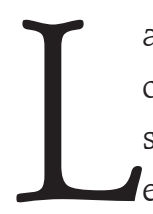

as comunidades y organizaciones transnacionales se han situado en el centro de la atención de organismos diseñadores de las políticas de desarrollo económico, a nivel nacional e internacional. Hay tres elementos mento de las remesas enviadas por los migrantes transnacionales ha generado

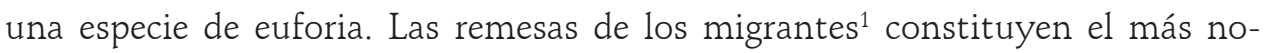
vedoso «mantra del desarrollo» entre instituciones como el Banco Mundial, los gobiernos y las organizaciones no gubernamentales (ONG) francesas y británicas (Kapur, 2004). Las remesas se perciben como fuentes de financiamiento generadas «desde abajo». Efectivamente, al examinar las cifras generales, las remesas anuales percibidas por los países en desarrollo se incrementaron más del doble durante la década de los noventa y han sido superiores, en un $20 \%$, a la asistencia oficial para el desarrollo (AOD) canalizada a estos países. Sin lugar a dudas, las remesas han estado a la par de la inversión extranjera directa en muchas partes del mundo en desarrollo. A medida que se verifica una tendencia ascendente en la tasa de migración transnacional, las remesas aumentan (ONU, 2004). Segundo, el conocimiento transferido a través de las redes de científicos, así como expertos, del Norte y Sur es visto, cada vez más, como una «circulación de cerebros» que resulta benéfica para todos los involucrados (Findlay, 2003). La transferencia de ideas se advierte como una ayuda para el desarrollo y la transformación de los países, al participar en la sociedad del conocimiento, base para la innovación, la productividad y el desarrollo. Tercero, incluso la transferencia de las remesas políticas, es decir, las ideas concernientes al régimen de la ley, el buen gobierno, la democracia y los derechos humanos, han logrado notoriedad en las secuelas de los conflictos armados y en los esfuerzos de reconstrucción de los países devastados

\footnotetext{
${ }^{1}$ Aquí nos centramos en los lazos transnacionales que surgen de la migración de sur a norte y no en la migración dentro del mismo sur. Pero nótese que más de un $40 \%$ de los migrantes transnacionales se mueven entre los llamados países en desarrollo. Además, este artículo aborda a los migrantes transnacionales y no a los nacionales dentro de los Estados, aun cuando después pueden ser más numerosos. Para establecer una comparación: a principios del siglo xxi había cerca de 175 millones de migrantes transnacionales. En contraste, tan sólo India tiene 200 millones de migrantes internos y China tiene 120 millones. Tómese otro ejemplo: en Vietnam, entre 1994 y 1999, existían unos 4.5 millones de migrantes internos, en contraste con 300 mil que salieron del país en el mismo periodo. La migración de los más pobres tiene lugar, especialmente, entre y dentro de los países en desarrollo. Por ejemplo, muchos países del sur de Asia se basan, fuertemente, en la mano de obra barata proveniente de países vecinos, como los trabajadores procedentes de Indonesia, en el caso de Malasia. En cuanto a los refugiados, dos terceras partes viven en países en desarrollo y más de una tercera parte se encuentra en los países menos desarrollados. No obstante, en las últimas décadas la proporción de migrantes transnacionales, en comparación con la de migrantes internacionales, se ha visto incrementada (onU, 2004).
} 
por la guerra civil, lo cual se ha dejado ver últimamente en Somalia, Afganistán e Irak. A veces las diásporas compuestas por exiliados, refugiados y migrantes laborales son convocadas como mediadoras en la resolución de conflictos, tal es el caso de Sudáfrica o Nigeria (Shain y Barth, 2003).

El papel positivo que se le atribuye a la migración y la movilidad internacionales puede percibirse como sorprendente. Al fin que, desde hace mucho tiempo, la migración transnacional ha sido considerada como un fracaso en el desarrollo. Puede concebirse como una salida territorial o geográfica ante el fracaso del estado, junto con otras instituciones, para lograr bienestar y seguridad social (Hirschman, 1970). Actualmente las organizaciones internacionales, encabezadas por el Banco Mundial, las onG y los gobiernos de los Estados-nación califican a las remesas — capital financiero, conocimiento e ideas políticas - como una solución para el desarrollo. En las décadas recientes, hemos sido testigos de un incremento, lento pero sostenido, en la proporción de migrantes transnacionales como porcentaje de la población mundial, de 1 al 2\%, en los años sesenta, a cerca del 3\%, recientemente. Siendo así, habría de existir un potencial mayor para los flujos transnacionales como las remesas. No obstante que las suposiciones que subyacen a los efectos en el desarrollo son bastante problemáticas. Por ello nos centramos en algo diferente: no en el impacto sobre el desarrollo, sino en el papel de los migrantes y las personas en movimiento como sujetos transnacionales. Los académicos han reconceptualizado ciertas categorías de migrantes como actores transnacionales (Faist, 2004). Actualmente, las organizaciones internacionales y las ong han seguido el ejemplo.

En este análisis argumentamos que el nuevo entusiasmo, hacia el papel crucial de las comunidades transnacionales y organizaciones de migrantes, constituye un esfuerzo por fusionar los principios de la comunidad con los del mercado global. No obstante, existen puntos de compatibilidad e incompatibilidad. Además, los principios de la comunidad transnacional y del Estado-nación pueden entrar en discrepancia en el caso de quienes, habiendo optado por la alternativa de la salida, ejercen su voz porque toman parte en la toma de decisiones en sus lugares de origen, pero no se ven afectados por las consecuencias de esas medidas.

La principal inquietud es evidenciar de qué manera, los grupos y asociaciones transnacionales, interactúan con los principios del Estado y el mercado en los flujos que atraviesan las fronteras. Primero, żde qué forma la reflexión académica y el diseño de políticas, en torno al tema del desarrollo, han concebido el papel de las comunidades y organizaciones externas al Estado? Segundo, żde qué manera las actividades de las cámaras, grupos y organizaciones transnacionales, que encarnan algunos principios comunitarios, resultan complementarias o incompatibles con los de otras instituciones que funcionan según las lógicas del Estado y el mercado? En realidad, se entiende poco acerca de qué papel desempeñan los grupos y organizaciones transnacionales, frente al Estado y el mercado, cuando está implícita la transferencia de capital financiero a través de remesas e inversiones, conocimiento e ideas políticas. La perspectiva adoptada no es la del gobierno 
global, sino la de los sujetos transnacionales, comenzando por los migrantes mismos y por los espacios sociales transnacionales en los que habitan. En general, son dignas de atención las ideas en torno al papel de las comunidades en el desarrollo y de las comunidades frente a otros principios del orden social, como el mercado y el Estado. El mayor interés por el papel de las diásporas y las organizaciones migrantes transnacionales refleja los cambios conceptuales del desarrollo, mismos que sirven de guía a las políticas públicas de las instituciones y ONG nacionales e internacionales. El conjunto de problemas planteados se relaciona con la pregunta más general acerca de la relación cambiante entre comunidad, Estado y mercado, bajo las condiciones de lo que se denominan globalización.

Desde el punto de vista heurístico, cabe distinguir tres principios del orden social de manera tipo-ideal: comunidad, Estado y mercado. El principio de comunidad refiere a la noción de que el orden social presupone o, cuando menos, se beneficia de los derechos y obligaciones asociados con los miembros de una comunidad concreta de personas. Las comunidades constituyen el cemento que integra, a los miembros de colectividades concretas, en lazos de confianza, reciprocidad, lealtad y solidaridad; ligados por derechos y obligaciones mutuos. Los derechos y deberes delimitan los confines de la comunidad, y pueden fundamentarse en mecanismos como parentesco, conocimiento y valores compartidos, la creencia en instituciones comunes o la fe religiosa. Los límites del mercado son bastante diferentes en el sentido de que la competencia dispersa es impulsada, idealmente, por el interés de los agentes sociales en la adquisición consciente de bienes individuales, sin reparar en las otras personas. El principio del Estado consiste en el control jerárquico, la toma de decisiones vinculadas a la comunidad política. La autoridad debe servir al bien común, en nuestro caso, relacionado a la noción de desarrollo. Mientras que las comunidades se caracterizan por diversas nociones limítrofes entre «nosotros» $y$ «otros», al tiempo que los mercados existen sin demarcaciones geográficas, los Estados —al menos en sus encarnaciones modernas desde la paz de Westfalia - se definen por claros límites territoriales establecidos por su función de poner en práctica las decisiones vinculantes de la autoridad por la fuerza del poder y la legitimidad. En pocas palabras, comunidad, mercado y Estado son mecanismos maestros del orden social, los cuales se caracterizan por incompatibilidades que, no obstante, se requieren unos a otros para cumplir su función (Schmitter y Streeck, 1985; Offe, 2001). Empíricamente, el principio de comunidad se estudia observando las cámaras, grupos y organizaciones de personas en movimiento; el principio del Estado, los actores gubernamentales y públicos; el principio del mercado, a su vez, las firmas.

Este trabajo examina los diversos sujetos transnacionales, es decir, los grupos y organizaciones de personas en movimiento, incluidas las familias, grupos de oriundez, comunidades epistémicas y diásporas. Esas formaciones colectivas transnacionales movilizan formas muy diversas de capital: financiero, como dinero en forma de remesas o inversiones; conocimiento y experiencia profesional, 
e ideas políticas, como las referentes a las formas de gobierno, derechos, responsabilidades y democracia. El capital financiero, el conocimiento y las ideas políticas pueden movilizarse dentro de los confines del capital social —es decir, las diversas formas de reciprocidad y solidaridad (Faist, 2000)—, llamado algunas veces remesas sociales (Levitt y Nyberg-Sørensen, 2004).

El análisis del papel de los sujetos transnacionales requiere un enfoque transnacional, más allá del concepto binario tradicional que enfatiza los procesos emigratorios, desde países concretos, e inmigratorios en otros países en particular, incluyendo el posible retorno a las naciones de origen. En contraste, la migración y la movilidad transnacionales han de entenderse como procesos multifacéticos, mismos que vinculan a los países de origen y destino, así como a la migración que prosigue más allá. Esos espacios sociales se caracterizan por transacciones densas y continuas allende las fronteras (Faist, 2000; Basch et al., 1994). Por lo tanto, el concepto sugiere que no sólo se observe a quienes fueron migrantes transnacionales que, eventualmente, se establecen en el norte, regresan a su país de origen o participan en la migración posterior. En vez de ello, independientemente de dónde se establezcan, las personas pueden conservar lazos transnacionales que impactan sus países. Por igual, la atención no ha de centrarse sólo en los migrantes que se establecen en el extranjero por un periodo significativo de tiempo, sino también en aquellas personas que participan en la movilidad a corto plazo. Son ejemplos de espacios sociales, formados por migrantes y personas en movimiento, las familias transnacionales, las asociaciones de oriundos, las comunidades epistémicas de expertos y científicos, las congregaciones religiosas globales y las comunidades étnicas e incluso nacionales. ${ }^{2}$

Consecuentemente, la noción de desarrollo se entiende aquí de acuerdo a los diferentes tipos de comunidades transnacionales: en el caso de las familias transnacionales, como un seguro informal frente a los riesgos económicos y como una inversión para el futuro de los hijos; en las comunidades de oriundos, el me-

\footnotetext{
${ }^{2}$ Cabe matizar que no todos los migrantes transnacionales, o personas con alta movilidad, desarrollan lazos transnacionales densos y continuos. Algunos realmente se desarraigan, como sucedió con los migrantes alemanes del este de Europa a fines del siglo xx. Otro problema de la investigación transnacional ha sido la agregación exagerada. En los discursos académicos y públicos, los migrantes, en cuanto actores que cruzan fronteras, son concebidos principalmente como «diáspora». Este término tiende a tratar, a los emigrantes de un determinado Estado-nación, como un todo, por ejemplo, la diáspora hindú o la diáspora china. Esto presenta tres problemas: 1) implica una relación unilateral, al enfocarse sólo en el país de origen, en adición al concepto tradicional de diáspora como una dispersión forzada, la cual limita la perspectiva que considera relaciones en dos sentidos; 2) la diáspora religiosa o nacional puede no captar la manera en que se conciben a sí mismos sus integrantes. Por ejemplo, no todos los migrantes provenientes de Turquía se consideran turcos, algunos se identifican como kurdos, y 3) existen diferentes niveles de agregación: familias, pueblos, regiones, naciones, lealtades interculturales y práctica de religiones. Es necesario analizar la noción de diáspora y dejar espacio para los diferentes tipos de comunidades transnacionales. Aquí el término se reserva para las grandes comunidades político-nacionales de autoadscripción.
} 
joramiento de la infraestructura y la provisión de bienes colectivos en el ámbito local (p. ej., educación y salud); en las redes de empresarios, oportunidades de inversión y rentabilidad; en las comunidades epistémicas, el flujo irrestricto de conocimiento, y en las comunidades nacionales, un alto grado de autonomía política, que a veces implica la formación de un Estado-nación independiente. Todas estas nociones se asemejan al mínimo común denominador que, el concepto desarrollo, ha significado desde fines de los años cuarenta del siglo pasado, específicamente por lo que hace a la vaga esperanza de progreso y mejoría de la zona del mundo que se considera subdesarrollada - para una aguda crítica véase (Escobar, 1995) - El enfoque transnacional significa no sólo examinar a los países en desarrollo y transformación, sino también a los países altamente industrializados. En este último caso, lo que importa es la contribución de los migrantes al seguro social, la provisión al bienestar, la reducción del diferencial en el mercado laboral - entre la economía informal y los sectores altamente calificados - o la difusión de los valores de la democracia y los derechos humanos por los migrantes.

La primera parte de este trabajo esboza la adopción, por las organizaciones internacionales y los gobiernos de los países de la Organización para la Cooperación y el Desarrollo Económicos (OCDE), del concepto comunidad como una categoría referencial en el pensamiento del desarrollo a lo largo de las últimas tres o cuatro décadas. La segunda parte discute el papel de los tres principios del orden social, en particular la comunidad frente al Estado y el mercado en los procesos de desarrollo; se examina de qué manera las organizaciones y los grupos migrantes han complementado, o han sido incompatibles con, los principios del Estado y del mercado. El análisis transnacional requiere que se examinen los vínculos entre los países de emigración e inmigración, así como las regiones emisoras y receptoras, más allá de la interdependencia entre unidades cerradas en la apertura de espacios sociales transnacionales. La tercera parte se refiere a las implicaciones para la investigación futura y argumenta que el concepto de espacios sociales transnacionales —es decir, espacios «intermedios» entre lo local y lo global, así como entre Estados-nación- puede utilizarse como un instrumento para iluminar los dilemas de la democracia y la ciudadanía que cruzan las fronteras, sin recurrir simplemente a las nociones centradas en el Estado-nación. En contraste con ideas recientes sobre el equilibrio entre Estado, mercado y comunidad en el desarrollo, los Estados pueden ser traídos a colación para evidenciar la oportunidad de la emergencia de espacios sociales transnacionales y, en consecuencia, el papel de los grupos y asociaciones transnacionales en la política de desarrollo.

\section{EL PAPEL DE LA COMUNIDAD EN EL DESARROLLO}

La importancia de la comunidad, como pilar del desarrollo, se ha incrementado en las últimas tres décadas. El enfoque más reciente de la política de desarrollo 
basada en los sujetos transnacionales, en el contexto del incremento del flujo de remesas de los migrantes, se ajusta a un patrón en el que los papeles del Estado y el mercado han sido reevaluados, desde sus cimientos, por las organizaciones internacionales de desarrollo. Se ha dado un cambio evidente en la reflexión acerca de las políticas internacionales de desarrollo, lo que ha llevado al redescubrimiento de la migración transnacional como un conjunto de procesos que implica la transferencia de recursos, desde los países desarrollados a países en desarrollo. Las instituciones internacionales como el Banco Mundial, además de las organizaciones y gobiernos nacionales, atribuyen un papel creciente en los procesos de desarrollo a las comunidades, particularmente a las comunidades transnacionales (Biao, 2005). Hace años, John Kenneth Galbraith describió la migración como la «acción más antigua contra la pobreza» (Galbraith, 1962; citado en House of Commons, 2004). ${ }^{3}$ Esta intuición parece descansar en fundamentos sólidos de la teoría económica. Si se liberalizara la migración transnacional, podrían derivarse grandes ganancias equivalentes, quizá, a la conclusión de la actual «ronda de desarrollo» de la Organización Mundial de Comercio (OMC). Idealmente, la migración descendería bajo un sistema global de libre intercambio de todos los factores de la producción, incluida la mano de obra, debido al factor de ajuste de precios, es decir, la tendencia de los salarios a ajustarse en la medida que los trabajadores se trasladan de las regiones más pobres a las más ricas del mundo. Según la teoría neoclásica, el comercio y la migración son sustitutos: los países con mano de obra relativamente más barata exportan bienes de mano de obra intensiva o trabajadores. Con el tiempo, las diferencias en los precios de los bienes y los salarios se reducirían gracias a un comercio más libre (Fischer, Martin y Straubhaar, 1997). Una consecuencia paralela sería una caída significativa en el nivel salarial y, probablemente, en algunos rubros del Estado de bienestar en los países de inmigración altamente industrializados (Hamilton y Whaley, 1984). Ésta es también una de las razones por la que no vemos un movimiento libre, es decir, una migración sin fronteras y, en cambio, observamos límites bastante estrictos de los Estados de bienestar a la inclusión de los recién llegados.

Como suele suceder, han proliferado voces críticas que cuestionan las expectativas excesivamente simplistas y las causalidades espurias. Sin lugar a dudas, los flujos de remesas que pasan por los migrantes y las comunidades trans-

\footnotetext{
${ }^{3}$ El patrón regional de distribución es el siguiente: América Latina y el Caribe reciben la mayor parte de las remesas (30 mil millones), seguidos por el sur de Asia (18 mil millones), el oriente y el Pacífico de Asia (18 mil millones), el medio oriente y el norte de África (13 mil millones) así como el centro y este de Europa (diez mil millones). El África subsahariana, que incluye a los países más pobres del mundo, recibe la menor cantidad de remesas (cuatro mil millones). En América Latina, las remesas alcanzan el 2\% del PIB. No obstante, en las economías menores la proporción es mucho mayor: el 29\% del pib en Haití y, en El Salvador, Honduras y República Dominicana, cerca del 15\% (Orozco, 2002).
} 
nacionales no son la panacea para subsanar los problemas del desarrollo. Después de todo, el despegue y el éxito de los procesos de desarrollo dependen, entre otras cosas, de las condiciones macroestructurales, como las reformas en la tenencia de la tierra, un clima favorable a la inversión, una burocracia y forma de gobierno transparentes e incorruptas, por mencionar entre las más obvias. En general, la evidencia de los efectos en el desarrollo es contradictoria y fragmentaria. Buena parte de la investigación que apoya las creencias acerca de los costos y beneficios globales de la migración se basa en estudios a nivel micro que no pueden demostrar, de manera convincente, la validez de sus conclusiones a nivel macro. Resulta muy problemático extrapolar la evidencia micro al nivel macro, sin especificar los mecanismos del proceso de agregación. En cuanto a la transferencia de conocimientos, puede que no sea innovador, simplemente, cambiar el nombre de lo que solía llamarse «fuga de cerebros» (brain drain) por "ganancia de cerebros» (brain gain) en alusión a todos los involucrados, es decir, los países de emigración e inmigración y las personas en movimiento. Ese recurso omite el hecho de que la migración produce efectos nocivos, debido a la salida de los profesionistas altamente calificados, como sucede con el personal de salud en el sur de África o con los científicos e ingenieros de los países en desarrollo, en donde hay escaso potencial para reemplazar a los que se van. En último lugar, en el caso de los exiliados, migrantes y refugiados como promotores de los derechos humanos y la democratización, se olvida el hecho de que algunos de estos grupos se encuentran en el centro mismo de la perpetuación de los conflictos violentos y no en su resolución: por ejemplo, el nacionalismo a larga distancia de los rebeldes Tigres Tamiles de Sri Lanka. Además, la Organización de las Naciones Unidas (ONU), en sus objetivos de desarrollo del milenio (ODM), no menciona a las migraciones transnacionales o a las diásporas vinculadas con los procesos de desarrollo. Muy pocos de los documentos de estrategia de lucha contra la pobreza (DELP) reconocen a la migración o el refugio en conexión con el desarrollo. Hasta el momento, el papel de las comunidades transnacionales ha sido un tema emergente, discutido en foros más especializados como la Comisión Global sobre la Migración (CGM) establecida en la ONU. Aun así, estas instancias no han puesto, seriamente, el énfasis en los sujetos transnacionales como portadores de desarrollo.

El retorno de la comunidad en el pensamiento sobre las políticas de desarrollo puede verse como un proceso acumulativo. Una breve revisión de la historia de las ideas sugiere cuatro etapas sucesivas. La primera refiere al prolongado periodo después de la segunda guerra mundial, en el que se suscitó el modelo de industrialización sustitutiva de importaciones bajo los auspicios del Estado. La teoría de la modernización, de las décadas de los cincuenta y sesenta, atribuía un papel activo crucial a los grupos y organizaciones pequeños (Huntington, 1966). Ese estado de cosas comenzó a cambiar en la segunda etapa, caracterizada por el llamado del Banco Mundial, en 1973, a dirigir los esfuerzos de desarrollo hacia los «más pobres de los pobres». Esta proclama desencadenó un cambio en el enfoque 
que lo alejaría del crecimiento hacia la redistribución y la equidad. De manera comprensible, este cambio conceptual implicó un giro hacia un énfasis creciente en la participación comunitaria en el desarrollo. Ya fuera que a las estrategias de desarrollo se les denominara "primero el granjero», "desde abajo» o «de las bases», el acento se daba en la descentralización, la localización y la satisfacción de las necesidades humanas básicas de alimentación, refugio, salud y lo que en la actualidad llamamos seguridad social.

El giro hacia la comunidad coincidió con las críticas al Estado «desarrollista» $y$, sobre todo, con el creciente rol concedido al mercado. Las organizaciones internacionales, como el Banco Mundial, convocaron a una mayor participación en el mercado global (McMichael, 1996), en claro contraste con los conceptos inspirados por la teoría de la dependencia, la cual abogaba por una disociación parcial de la participación en el mercado mundial (Senghaas, 1974). Gracias a la influencia de la crisis de la deuda en América Latina, en los setenta y ochenta, así como a la implosión de los Estados poscoloniales en algunas partes de África y otros lugares, los estudios académicos también enfatizaron las distorsiones económicas efectuadas por las elites en busca de ganancias al mando de los Estados depredadores (Bates, 1988). Las instituciones internacionales de desarrollo comenzaron a confiar más en la operación de mercados relativamente libres de ataduras, así como en los beneficios que el crecimiento impulsado por el mercado podría llevar a las sociedades, cuyo potencial de crecimiento económico se había frenado por las instituciones estatales a las que se consideraba ineficientes. Un resumen de esta tendencia se bautizó como Consenso de Washington. Efectivamente, las organizaciones internacionales, como el Fondo Monetario Internacional (FMI), presionaron a los gobiernos deudores para que basaran su política en las señales de los precios del mercado, al tiempo que abogaban por la privatización, desregulación y demolición de derechos laborales y subsidios sociales (Chang y Graebel, 2003). Las agencias internacionales de desarrollo, cada vez más, sobrepasaron a los gobiernos de los países subdesarrollados y optaron por estrechar lazos con agencias no gubernamentales, locales e internacionales.

La tendencia a la mercadización coincidió, quizá de manera accidentada pero no azarosa, con una noción antiestatista, la cual planteaba que el desarrollo conllevaba la dotación de poder (empowerment) a las comunidades e individuos para que ellos realizaran el "proyecto de desarrollo». Obviamente, el énfasis en la autonomía local y en la participación de las bases se dirigía a aportar un útil correctivo a las estrategias de desarrollo desde arriba, instrumentadas en el pasado. En pocas palabras, con la retirada del Estado como mecanismo para la creación del orden social y de diseño de políticas, la comunidad surgió como mecanismo de compensación. En una paradigmática innovación conceptual del desarrollo, las agencias internacionales de este ámbito comenzaron a utilizar nuevos conceptos que, se suponía, impulsarían el desarrollo, al respecto, el concepto capital social fue uno de los más importantes (Evans, 1996). Conceptualmente, la noción 
de capital social se acerca a la vinculación entre los principios del mercado y la comunidad. ${ }^{4}$ Los recursos inherentes a los lazos sociales — reciprocidad, confianza y solidaridad - se conciben como constituyentes de un capital que produce intereses; por ejemplo, el acceso a recursos financieros y otros bienes sociales. Los principales actores en las políticas de desarrollo, como el Banco Mundial y un gran número de ONG, propagaron modalidades participativas de desarrollo a nivel local. La idea de globalización «desde abajo» se ha enfocado, lógicamente, en las diásporas y las comunidades transnacionales. En este proceso también se ha transformado el papel del Estado como principio del orden social en el desarrollo. Ahora se constituye en un proveedor de servicios para los mercados y, en parte, para las comunidades, con lo cual genera las condiciones para el intercambio mercantil a través del establecimiento de reglas, una democracia estable y la garantía de un mínimo de derechos humanos, civiles y políticos (Nuscheler, 2004). Dicho brevemente, las estructuras políticas y legales proporcionan la infraestructura necesaria para el crecimiento económico (North, 1990). Nociones como buen gobierno y régimen de la ley, en el contexto posterior a la "tercera ola de democratización» (Diamond, 1996), adquieren la mayor jerarquía dentro del universo de los conceptos del desarrollo.

En síntesis, se ha dado un cambio conceptual al reincorporar a la comunidad en el discurso sobre el desarrollo y, más recientemente, a los grupos así como organizaciones transnacionales. Aun cuando existe un fuerte vínculo entre los conceptos cambiantes y las políticas reales que se ejecutan, es necesario superar el supuesto papel de la comunidad, del Estado y del mercado para develar los distintos roles de cada conjunto de principios del orden social.

\section{LA COMUNIDAD FRENTE AL MERCADO Y EL ESTADO: COMPLEMENTARIEDADES E INCOMPATIBILIDADES}

Aun cuando los Estados vigilan sus fronteras y límites, en tanto que los mercados actúan en un mundo carente de fronteras, las comunidades ocupan un nicho distinto al crear un orden social que trasciende las líneas divisorias. El centro de la atención, aquí, se da en la manera en que los grupos de parentesco, las comunidades aldeanas, las redes empresariales, los grupos epistémicos y las diásporas interactúan con los actores en los Estados y los mercados.

\footnotetext{
${ }^{4}$ El capital social puede entenderse de dos maneras: 1) lazos sociales como recursos disponibles para las personas (Bourdieu, 1983; Loury, 1985), y 2) recursos como la reciprocidad y la solidaridad disponibles para los grupos que permiten la cooperación (Putnam, 1993; Faist, 2000).
} 


\section{El capital financiero como remesa: \\ pequeños grupos de parentesco}

Para muchas personas que pertenecen al tipo más pequeño de grupo transnacional, es decir, familias o grupos de parentesco, los lazos que van más allá de las fronteras y los modos de vida que surgen de la migración podrían servir como una estrategia de supervivencia, bastante cercana a la de generar ingresos a partir de la migración como mecanismo de seguridad (Olwig y Sørensen, 2002). Ello implica hogares divididos en diversos Estados y dos lugares de residencia. Las remesas monetarias, con frecuencia, vinculan a los inmigrantes con sus parientes, trasponiendo grandes distancias por medio de lazos de reciprocidad y solidaridad; por ejemplo, el intercambio intergeneracional, cuando los hijos trabajan en el extranjero y sostienen a sus padres de edad avanzada, además de otros miembros de la familia en su país de origen.

Las instancias de complementariedad, en las transacciones comunitarias con los principios del Estado y el mercado, son evidentes. Las transferencias que hacen los miembros de la familia son síntoma del doble papel de algunos inmigrantes, como proveedores para las familias en el país de origen pero, también, para las arcas del Estado de bienestar en el país en que están empleados. En los sistemas de seguridad social para las pensiones, por ejemplo, el promedio de edad de los inmigrantes, más jóvenes en comparación con el resto de la población, generan transferencias sustanciales. Un estudio realizado en Alemania, a fines de los ochenta, evidenció que los inmigrantes generaron beneficios positivos en el corto plazo en sectores seleccionados del Estado de bienestar. De unos 3.6 millones de personas, que inmigraron entre 1988 y 1991, se obtuvieron beneficios muy positivos. Según tal estudio, unos cien mil empleados inmigrantes generaron 30 mil millones de marcos para la seguridad social, mientras que los costos alcanzaron tan sólo 14 mil millones de marcos, lo que significa un considerable superávit de 16 mil millones (Barabas et al., 1992). Además, como ya se mencionó, los migrantes transnacionales pueden sostener a la parentela en el país de origen. Esas comunidades y países, con frecuencia, se caracterizan por la ausencia de sistemas de seguridad social organizados por el Estado y, si existen, no permiten niveles mínimos de vida.

Los límites de este doble papel se advierten en el flujo de remesas a lo largo del ciclo de vida de los migrantes. Estos flujos no son necesariamente estables. Hay una concepción general, en la literatura, acerca de que las remesas tenderán a disminuir con el tiempo, en la medida que los migrantes se comprometan más en el país donde residen (disminuirían en el caso de que se establezcan en el país de inmigración, y serían nulos en caso de regresar). Con frecuencia, se percibe que de tres a cinco años es el periodo máximo de envío de remesas, al tiempo que es frecuente que se suscite una caída particular en el momento en que el migrante consolida un estatus en el extranjero. Sobra decir que ese patrón no es inevitable 
y que puede verse afectado por el contexto macroeconómico y macropolítico, así como por los eventos vitales entre los migrantes y sus familias.

Un elemento adicional de complementariedad es macroeconómico. Algunos países de emigración, especialmente los principales receptores de remesas y aquellos en que esas transferencias alcanzan altas proporciones del producto interno bruto (PIB), han llegado a utilizar los montos de remesas, actuales y futuros, para aumentar su disponibilidad de créditos en el sector financiero. De esta forma, la solidaridad y reciprocidad de los migrantes, con sus hogares filiales en el país de origen, se han convertido en «futuros de divisas duras», utilizados como «seguridad intercambiable» para acceder a préstamos extranjeros, en economías cuyo acceso crediticio se había deteriorado en el mercado internacional (Guarnizo, 2003).

La aparente incompatibilidad de esas transacciones no está relacionada, directamente, con la actividad de las familias, sino con la manera en que los pequeños grupos de parentesco compiten con los bancos y otras instituciones del mercado, en tanto canales formales de remesas. En pocas palabras, los gigantes del mercado pueden, en algunos casos, competir con los sistemas de solidaridad como esquemas de transacción no oficiales que pueden ser, a veces, ilegales, de hawalla y hundi. Estos últimos están organizados sobre la confianza entre, por ejemplo, los miembros de comunidades religiosas y se utilizan en múltiples situaciones, como la diáspora judía. Básicamente, los migrantes que desean transferir sus remesas utilizan esos sistemas para trasladar dinero sin pagar altas comisiones. El extremo, el remitente envía información al receptor y las remesas se entregan inmediatamente, con base en la confianza mutua. Estas formas de transacción entran en discordancia con la participación, más reciente, de las grandes corporaciones financieras en el control de las transferencias de remesas en el mundo. Por ejemplo, Western Union y MoneyGram, en 1996, controlaban ya el 97\% del mercado de remesas y el $81 \%$ de los locales que, en Estados Unidos, se estimaban en 43 mil (Guarnizo, 2003). Mientras que el mercado México-Estados Unidos está dominado por las grandes corporaciones, las remesas al sur de Asia parecen basarse en canales no oficiales. Por ejemplo, un estudio en Bangladesh mostraba que el $40 \%$ de las remesas se envían a través de fuentes hundi informales; el $4.6 \%$, por amigos y familiares; el $8 \%$, por los migrantes a su retorno, y el $46 \%$, por fuentes oficiales. Para Pakistán, los altos ejecutivos de los bancos calculan el flujo real entre ocho y 10 mil millones de dólares, de los que sólo mil millones se envían, realmente, a través de los canales oficiales (Hugo, 2003). En el contexto de las secuelas del 11 de septiembre de 2001, diversos gobiernos occidentales han clausurado los canales no oficiales, bajo el argumento de que se les utilizaba para el lavado de dinero y para propósitos terroristas explícitos (Mellyn, 2003).

La compatibilidad entre las transacciones comunitarias y los esfuerzos estatales por evitar estas actividades también es dudosa. Es frecuente que, los estudios sobre remesas, supongan que los migrantes involucrados emigraron de manera más o menos voluntaria. Se da escaso énfasis a los refugiados o, más pre- 
cisamente, a quienes contaban con escasos grados de libertad al momento de su salida. Las relaciones contenciosas entre el Estado y los ciudadanos, en los países de origen de la emigración, pueden arrojar luz acerca de la resistencia, de los países de emigración, a inhibir las remesas, en especial cuando una de las motivaciones para emigrar era escapar de la influencia de gobiernos autoritarios. Además, si los migrantes sienten que los gobiernos, simplemente, buscan establecer un impuesto sobre su diáspora, se cuestiona el cumplimiento de esta imposición fiscal indirecta. En el caso de Eritrea, el joven Estado intentó gravar, a los expatriados, con el 2\%, el llamado «impuesto de curación», a fines de los años ochenta. Más tarde, el Estado utilizó los fondos para financiar la guerra contra Etiopía.

La protección de los derechos humanos, en los países de inmigración, puede no constituir un problema de incompatibilidad dado que, en la mayoría de ellos, se aplican las normas de los derechos humanos y laborales básicos, aunque con diferencias significativas al compararse a los países de la Unión Europea (UE) con los países del Medio Oriente y con las economías asiáticas de rápido crecimiento. En estas últimas, los derechos de los trabajadores migrantes parecen estar mucho menos protegidos, al menos en lo que respecta a las protecciones formales (Weiner, 1986). En lo que toca a los países de emigración, no sólo hay un problema de instrumentación. Es claro que hay un interés directo en las remesas. Y algunos países, como Filipinas, han ajustado sus sistemas educativos y de salud a la exportación de trabajadores y servicios (Martin, 2004). Esta estrategia implica una maximización del fenómeno emigratorio. Al mismo tiempo, la legitimación del régimen político requiere que los países de emigración atiendan los derechos humanos, civiles y sociales de la fuerza de trabajo migrante en el extranjero. La tensión entre los números frente a los derechos incide, claramente, en las condiciones bajo las cuales los miembros de los grupos familiares, en especial aquellos empleados en sectores críticos como los servicios domésticos y la construcción, son capaces de negociar los términos de su empleo (Rodríguez, 2002). ${ }^{5}$

Las incompatibilidades afectan de manera notable a los pequeños grupos, que se ven transformados como consecuencia del aprendizaje durante el proceso mismo de la migración. En algunos casos, la «feminización de la migración» ha llevado a la transformación misma de las relaciones de género, mismas que constituían la médula de los arreglos migratorios en los grupos de parentesco grandes

\footnotetext{
${ }^{5}$ Existe una clara distinción entre el empleo legal, bajo el cual los trabajadores pueden recurrir a medios legales, y el empleo ilegal, que no concede derechos sociales. Aun cuando esta diferencia es importante, las relaciones en el empleo ofrecen distintas oportunidades para las diversas categorías de migrantes. Por ejemplo, para los trabajadores que son enviados al extranjero como mano de obra contratada, los derechos sociales en el país del empleo temporal pueden no ser muy importantes. Además, los trabajadores de temporada pueden no tener la flexibilidad que desearían, si se les contrata bajo programas de empleo, ya que quienes ofrecen el puesto por lo general contratan a quienes consideran los más dóciles (Faist, 2003).
} 
y pequeños. En Bangladesh, la migración de las mujeres hacia Malasia tuvo, como consecuencia, el cambio de las prácticas sociales. Una vez que comenzó el flujo de mujeres desde Bangladesh a Malasia, las mujeres jóvenes procuraron emigrar, lo que llevó a un aumento en la independencia económica. Quienes participaban en la migración prestaban a otras mujeres y también participaban en la fuerza de trabajo en Bangladesh. Malasia, que también es un país musulmán, se considera un modelo a seguir para Bangladesh. Dado que la participación femenina en la fuerza de trabajo en Malasia es relativamente alta, las mujeres migrantes, e incluso quienes no lo son, adoptaron algunas de las nuevas prácticas de Bangladesh (Dannecker, 2005). Empero, asimismo sabemos de algunos otros casos en los que las prácticas transnacionales exacerbaron las estructuras de poder asociadas al género, en especial cuando el control de las remesas financieras permanecía en manos de los hombres (acerca de El Salvador: Mahler y Pessar, 2001). Estos ejemplos sugieren que los grupos transnacionales no siempre deberían verse como actores unitarios en todos los aspectos, sino que, en cambio, deben percibirse como colectivos sociales formados, algunas veces, por lazos sociales y simbólicos conflictivos.

\section{El capital financiero como inversión: asociaciones de oriundos}

Un enfoque centrado en las comunidades convierte a las transacciones transnacionales, en su mayoría, en transferencias translocales, es decir, relaciones entre localidades por encima de las fronteras de los Estados-nación. Los ejemplos son numerosos y las comunidades de los pueblos se presentan en diversas formas, entre ellas, las asociaciones de oriundos en México, las asociaciones de retorno en Jamaica o las fundaciones caritativas en Egipto. Esas colectividades proporcionan recursos significativos para el desarrollo de la comunidad a nivel local, es decir, participan en el financiamiento de materiales para la construcción del templo del pueblo de origen, recaban dinero para mejorar los sistemas de agua potable y alcantarillado o para optimizar la prestación de servicios de salud o educativos, además de ayudar a organizar los esfuerzos de apoyo tras los desastres naturales, así como canalizar las remesas, en especial en el continente americano.

Mientras que los países tradicionales de emigración, como Italia, hace mucho tiempo que cuentan con políticas y programas para sus (antiguos) ciudadanos que viven en el extranjero, sólo hasta años relativamente recientes, los países de emigración han remodelado su relación con las asociaciones de oriundos, con frecuencia de manera reactiva (para el caso de México: Goldring, 2002). Todavía más recientemente, las organizaciones internacionales han captado la posibilidad de que las comunidades transplantadas puedan ir más allá de la conservación de la cultura y dar sentido, en cambio, a una porción considerable de la estrategia de desarrollo económico para su país de origen (Lucas, 2001). La complemen- 
tariedad de las actividades de las asociaciones de oriundos y del Estado puede verse, fácilmente, cuando las comunidades y los Estados cooperan para mejorar la infraestructura en las regiones de origen. Un ejemplo bastante conocido es el Programa Tres por Uno en México, un ejemplo de la asociación público-privada en la política de desarrollo. Cada dólar de las remesas de las asociaciones de oriundos, destinado a proyectos de desarrollo aprobados por el gobierno, recibe un dólar de financiamiento de cada uno de los gobiernos federal, estatal y municipal. Otro ejemplo se refiere al turismo proveniente de las comunidades de emigrados hacia su «viejo país», en casos que van desde Irlanda hasta Vietnam. Es claro que, como en el caso de las remesas familiares, las asociaciones de oriundos privilegian ciertos lugares. Las fricciones entre las comunidades y los Estados surgen cuando las asociaciones persiguen objetivos políticos distintos de los propuestos por los gobiernos locales, regionales o nacionales. Esta respuesta de los Estados ha sido, por una parte, la represión y la vigilancia de los emigrantes en el extranjero, pero, por la otra, también esfuerzos más vigorosos, en ocasiones, por atender los intereses de la diáspora, por ejemplo, ofreciendo servicios a través de las instituciones consulares o de campañas políticas en el extranjero, como sucede en los casos de México, Haití y República Dominicana en Estados Unidos.

No obstante, hay incompatibilidades que van más allá de la divergencia de intereses y que plantean dilemas más fundamentales. Las organizaciones y grupos transnacionales pueden, simultáneamente, salir y expresar su voz, lo que se facilita por la movilidad geográfica y se fortalece por los lazos transnacionales. Aunque la complementariedad, entre la opción de salida y de voz, puede ser plausible desde un punto de vista normativo, como un mayor espacio de maniobra para quienes se trasladan, la transnacionalización de la participación política genera tensiones entre las personas y asociaciones con acceso a la movilidad, con aquellas que no se trasladan. Se suscita el dilema fundamental surgido del principio democrático de que quienes toman las decisiones deben ser parte de quienes se ven afectados por ellas, aunque los transnacionales participan en la toma de decisiones pero, cuando se trata de las consecuencias de las medidas, actúan como terceros. Este dilema fundamental es particularmente notorio en los países en transformación que han establecido una estructura que alcanza a los emigrantes en el extranjero, como en el caso de México. Existe una amplia variedad de instrumentos, que van desde el Programa Paisano, las matrículas consulares, el Instituto de los Mexicanos en el Exterior y los esfuerzos por institucionalizar la doble ciudadanía junto con los derechos políticos, como la iniciativa para la doble ciudadanía (1996) y la aprobación del voto extraterritorial para las elecciones federales de 2006. Esos programas pueden estimular y promover las asociaciones transnacionales y las formas transnacionales de ciudadanía. En el ámbito local, sin embargo, esas formas transnacionales no son inocuas porque, muy frecuentemente, una parte considerable de las llamadas comunidades de origen reside (temporalmente) en el extranjero. Este último es un efecto de la migración en 
cadena. El problema no es tan pernicioso a nivel nacional porque, por lo general, un porcentaje mucho menor de la población está involucrado en la migración transnacional. El patrón dominante, de la migración transnacional, es que existen pocos migrantes desde la mayor parte de los lugares y muchos de unas cuantas localidades, si se toma a los estados como la unidad de análisis más amplia. En esencia, la transnacionalización hace que se ensanche la combinación entre la salida y el ejercicio de la voz de manera sostenida y, por lo tanto, contribuye a las oportunidades desiguales para el ejercicio de los derechos políticos.

\section{Capital financiero en forma de inversiones:}

redes de empresarios

Algunas veces, los emigrantes que viven en el extranjero, junto con sus hijos, son vistos por los gobiernos del país de origen como «mediadores efectivos» (tal es el caso de China) que juegan un papel crucial en la intermediación para las inversiones extranjeras o para invertir directamente. No obstante, también hace tiempo que se reflexiona en torno a que el desarrollo definido como crecimiento económico no incide, principalmente, en el flujo de capital financiero, sino en el espíritu empresarial (Hirschmann, 1947). Los empresarios, en su calidad de comunidad práctica, pueden promover una atmósfera en la que puede crecer ese espíritu empresarial de los «protestantes» y de otro tipo de espíritu que desemboca en el éxito económico. Ejemplos a la mano lo constituyen los emigrantes de China continental, Taiwán e India. Los hindúes en el extranjero, establecidos en el Valle del Silicón, por ejemplo, contribuyeron al surgimiento de la región en torno a Bangalore como el centro de la industria hindú dedicada a la tecnología de la información. Los emigrantes hindúes que trabajaron como expertos altamente especializados, en el Valle del Silicón, invirtieron en la pujante industria de la tecnología informática en India. Los especialistas en programación, en India, ya contaban con empleo en empresas del extranjero para procesar datos y desarrollar programas. Los inversionistas hindúes del Valle del Silicón añadieron un espacio adicional para el establecimiento de empresas en India. Otras compañías extranjeras, provenientes de Estados Unidos y Europa, siguieron el ejemplo (Cornelius, Espenshade y Salehyan, 2001). La experiencia taiwanesa es similar a este caso (Tseng, 2000).

En casos como éste, que involucran un amplio sector terciario, es decir, un sector de la población migrante que vive en el extranjero educado en universidades y posgrados, se constituye un potencial para la inversión extranjera. Nuevamente, unos 20 millones de ciudadanos viven en el extranjero. Esta diáspora solamente es superada en tamaño por China. Se calcula que el ingreso de esta categoría asciende a más de una tercera parte del PIB de India. Por ello, no sorprende que la denominada comunidad de «hindúes no residentes» (HNR) aportara el 10\% de la inversión extranjera directa (IED) en India, así como una porción considerable del capital mixto. 
La República Popular de China puede servir como un caso por excelencia, ya que cerca del $50 \%$ de la IED proviene de los, aproximadamente, 30 millones de chinos en el extranjero. Los sucesivos gobiernos del país asiático han generado incentivos para que los chinos, desde el extranjero, inviertan en algunas áreas empresariales selectas (Saxenian, 2002). Sin lugar a dudas, las cadenas productivas globales, en este caso el desarrollo y procesamiento de programas computacionales, han hecho que inversiones como éstas sean más probables y rentables. No obstante, sabemos muy poco acerca de las redes y cámaras que sostienen los empresarios entre sí, al igual que de los intermediarios que los conectan en el país de origen. Necesitamos saber más acerca de cómo los empresarios actúan como intermediarios, como comunidades intermedias, como a veces lo hacen los llamados «trabajadores transnacionales» o «retornados temporales» que laboran en regiones de emigración e inmigración, al tiempo que desempeñan el papel de mediadores que vinculan a las empresas en las dos regiones, además de hacerlo con sus redes personales, siendo portadores del conocimiento tecnológico y de mercado. Parece factible suponer que unos cuantos de los expatriados, que invierten en sus países de origen, tienen las ventajas de quienes lo hacen desde dentro, como el conocimiento del idioma y las costumbres locales, además que es probable que gocen de la confianza de los burócratas que administran la planeación económica (Rauch, 2001).

Los gobiernos han puesto en práctica un conjunto de políticas para atraer tanto a los emigrantes altamente capacitados, como a quienes retornan, además de promover que quienes se quedan en el extranjero conserven lazos productivos. Por ejemplo, el gobierno hindú ofrece estímulos impositivos para los expatriados y trata de utilizar sus conocimientos, consejos e ideas para equipar mejor a las compañías hindúes, a fin de generar oportunidades para las compañías de India en el extranjero. Un instrumento simbólico, pero altamente visible, ha sido conceder un estatus especial de residente para los empresarios expatriados, muy similar a la doble ciudadanía. Ese estatus ha generado mayores opciones de ingreso a los grupos privilegiados.

Este ejemplo esboza ya algunas incompatibilidades potenciales entre las comunidades y los Estados. El Estado chino, por ejemplo, estimula los flujos de capital financiero pero, ciertamente, se opone a la importación de ideas políticas por los expatriados. Las ideas de los expatriados, respecto a la liberalización del régimen político y un mayor reconocimiento de los derechos humanos junto con los ideales democráticos, evidentemente no han sido bien recibidas; empero, los grupos empresariales que participan en la transferencia de capital económico, en contraste con la transferencia de capital político, son distintos al de los estudiantes.

El espinoso tema de la selectividad del desarrollo, a través de la transnacionalización, es aquí, pues, más evidente que en el caso de las remesas. Los Estados y las elites económicas se unen para patrocinar la inversión, quizá en detrimento de otros sectores de la educación y la economía. El gobierno hindú, por ejemplo, ha patrocinado fuertemente a los institutos avanzados de enseñanza, los Insti- 
tutos Hindúes de Tecnología (IHT). Ese esfuerzo concertado no se hace visible cuando se analiza la educación básica. Ciertamente, en este caso los gobiernos federal y provincial han generado las condiciones para que las comunidades de empresarios ofrezcan servicios e inversión. Por causa de la coalición de Estados y comunidades de empresarios, en la planeación y puesta en práctica de las inversiones extranjeras directas, sería exagerado considerar a tales procesos como desarrollo «desde abajo» (Bhagwati, 2003).

Para los países de inmigración, el espíritu empresarial inmigrante o étnico puede ser parte de los benéficos lazos de negocios transnacionales. Los estudios realizados en Canadá han mostrado que un incremento al doble en la migración capacitada, procedente de Asia, significó un incremento de 74\% en las importaciones asiáticas en Canadá (Page y Adams, 2004). Además, las iniciativas empresariales étnicas pueden ser instrumentales para la creación de empleos para los inmigrantes y los nativos. Los mercados pueden ampliarse en dos direcciones. Primero, la nostalgia por parte de los migrantes, en torno a los alimentos y productos del país de origen, genera mercados para esos productos en el país de inmigración, estimulando la producción local y el comercio internacional (por ejemplo, los inmigrantes turcos en Alemania). Segundo, los empresarios migrantes pueden invertir en los países de origen y contribuir así, de manera directa, al desarrollo económico en el extranjero. Aun cuando existe un enérgico desacuerdo acerca de los beneficios exactos que los llamados nichos étnicos, los enclaves y los mercados étnicos proporcionan a cada categoría — es decir, los empresarios étnicos frente a los trabajadores del mismo grupo étnico (Sanders, 2002) - la iniciativa empresarial migrante es un ejemplo por excelencia de cómo el capital financiero sigue a las personas o, más precisamente, el capital acumulado por la gente que primero fue atraída al extranjero por el capital. En todos estos procesos, el capital social constituye un mecanismo crucial de vinculación.

\section{Conocimiento:}

comunidades epistémicas

Las comunidades epistémicas de académicos y expertos constituyen colectividades ejemplares de práctica sin que se de propincuidad. Los científicos y los expertos profesionales comparten modelos, teorías e incluso estilos de vida que se caracterizan por una marcada movilidad geográfica. Recientemente, importantes actores políticos, como las organizaciones internacionales y los gobiernos, han comenzado no sólo a considerar la emigración, reemigración o retorno de los profesionales altamente calificados, sino también la formación de redes transnacionales. Este cambio de perspectiva, en parte, es resultado del hecho de que muchos de quienes están altamente calificados no regresan a las regiones de origen, aunque, de cualquier modo, forman redes epistémicas por encima de las fronteras en 
las que, algunas veces, participan los países de origen. Por ejemplo, la mitad de los estudiantes extranjeros que obtienen sus doctorados en Estados Unidos permanecen ahí cinco años después. La OCDE (1998) calcula que la fuga total de cerebros de los países en desarrollo, hacia los países de la OCDE, es de cerca de 12.9 millones de personas, con siete de ellas tan sólo en Estados Unidos. El reverso de la medalla es el flujo masivo desde las regiones de emigración. Según el Banco Mundial, África perdió a una tercera parte de sus ejecutivos entre 1960 y 1987 (Stalker, 1994). En pocas palabras, el papel del intercambio de conocimientos, para el crecimiento económico y el desarrollo, ha recuperado importancia en los últimos años. Las transferencias de recursos de un país a otro se discuten, actualmente, dentro del marco de la sociedad del conocimiento (Stehr, 1992). Hay múltiples declaraciones acerca de la importancia de la transferencia de conocimientos y la cooperación científica para el desarrollo (Banco Mundial, 1999). En relación con las políticas públicas, se han aumentado los esfuerzos por conectar las políticas de migración con las políticas de investigación en los países en desarrollo, los países en transformación y los países industriales (BMz, 2001).

Cabe hacer notar que el análisis académico de las consecuencias para el desarrollo, que tiene la movilidad de las personas altamente calificadas, se ha equiparado con el de las expectativas políticas: en la década de los sesenta, la mayoría de los análisis sostenían la idea de una "ganancia de cerebros», provenientes de los países en desarrollo, y la movilidad se veía como un recurso para modernizar a tales naciones. En las décadas de los setenta y ochenta, era verdad lo contrario, es decir, se impuso la visión más crítica de una «fuga de cerebros», con la suposición subyacente de que la emigración perjudicaba a los países en desarrollo. Esto no sorprende porque esos estudios situaban, al fenómeno, dentro del paradigma de la literatura de la dependencia. En el curso de los años noventa, de nuevo se transformó el humor académico y político de moda. Los expertos y los políticos de los países industriales, que requerían especialistas en tecnología altamente calificados, afirman que existe una "circulación de cerebros», una expresión aparentemente neutral (Appleyard, 1999). Hay quienes afirman que existen beneficios mutuos para todos los actores involucrados. En los países altamente industrializados, las políticas públicas dirigidas al reclutamiento de migrantes, con una gran capacitación, incluyen esfuerzos por atraer estudiantes internacionales. Subsecuentemente, algunos países de la OCDE, como Alemania, recientemente han cambiado su legislación para permitir que los estudiantes internacionales permanezcan o reingresen una vez que han terminado sus estudios. Además, los países de emigración han comenzado a promover iniciativas con el objeto de revertir la «fuga de cerebros». Los ejemplos incluyen los esfuerzos del gobierno hindú por patrocinar las inversiones, en el sector de la tecnología de la información, de los expatriados.

Hay diversos resultados posibles de la transferencia de cerebros: 1) fuga de cerebros seguida de una ganancia de cerebros; 2) fuga de cerebros, y 3) una «cadena global de cerebros». La primera posibilidad es la de una pérdida de cere- 
bros seguida de una ganancia. Es frecuente que, en el momento de la salida, se dé un déficit, seguido de algunas posibles ganancias no sólo para los migrantes y los países de inmigración, sino también para los de emigración. La emigración de las personas altamente calificadas puede ser ventajosa para quienes permanecen en el país de origen, cuando las personas educadas se van y luego reportan, a su regreso, que han tenido éxito económico. Esa comunicación genera un incentivo para quienes se han quedado para que mejoren su conocimiento y capital social al invertir, por ejemplo, en educación superior. Estos procesos pueden suscitarse a gran escala y sólo un pequeño porcentaje, de aquellos cuyos bienes de capital han mejorado realmente, dejarán el lugar, mientras que el resto se quedará en el país de origen y se beneficiará de la educación en el país natal (Stark y Wang, 2001). La segunda posibilidad es la fuga de cerebros, en especial en los países más pobres, que carecen de capacidad de reemplazo. Los ejemplos empíricos incluyen a la llamada «fuga de cuidadores de la salud» proveniente de Zambia, Liberia y Zimbabwe. Las enfermeras y los médicos, provenientes de estos y otros países del África subsahariana, cubren los huecos en los sistemas de salud de los países desarrollados, aunque el déficit en sus países de origen es muy considerable, más aún por casos como la pandemia de VIH/Sida en el sur de África. Mientras tanto, los sistemas de salud en los países de la OCDE, como Reino Unido, por ejemplo, se benefician de estas salidas: uno de cada diez empleados del sistema de salud provenía de los países en desarrollo, a principios de los noventa. Para 2002, en un periodo de diez años, más de cinco de cada diez eran originarios de regiones fuera de Reino Unido. ${ }^{6}$ La tercera posibilidad es la de una cadena global de cerebros o "cascada en etapas», que podría implicar tanto la pérdida como la ganancia de cerebros. Un ejemplo notable es el de los médicos que se van de Canadá a Estados Unidos, quienes, a su vez, son reemplazados por sudafricanos en Canadá. En el extremo de la cadena, los médicos cubanos se trasladan a Sudáfrica.

En los países de inmigración, la idea de globalización económica ha conducido a un mayor esfuerzo, de las compañías y los Estados, para atraer personas graduadas al sector terciario. Al captar a los estudiantes internacionales y a los futuros científicos, los países de la OCDE han modificado su legislación, cambiando de una estrategia de tarjeta roja a una de alfombra roja. El mayor recurso a los trabajadores del conocimiento rememora la «compra de cuerpos» y el robo de

\footnotetext{
${ }^{6}$ Otra posibilidad, asociada con la movilidad de personas altamente calificadas, es el «desperdicio de cerebros», es decir, profesionistas que se emplean como trabajadores domésticos en los países de inmigración (por ejemplo, las enfermeras filipinas en los países del Golfo Pérsico en el sector doméstico) o trabajadores altamente calificados que regresan a su país de origen, pero no pueden emplear sus habilidades, como sucede con los científicos en las disciplinas naturales que no pueden acceder a los laboratorios apropiados. El peor escenario es llamado «desertificación de cerebros». En este caso, las personas altamente capacitadas no regresan y no conservan lazo alguno con quienes se quedaron en el país de origen.
} 
trabajadores, una estrategia bien conocida, empleada por muchos países al emular el éxito de los líderes económicos, por ejemplo, en la Inglaterra del siglo XVIII que atraía a trabajadores de las tierras bajas (Chang, 2002). La diferencia reside, sin embargo, en que actualmente no son los países que intentan emparejarse los que se involucran en el robo, sino los que están más adelantados. Estados Unidos es, en nuestros días, el único país con un saldo positivo frente a todas las demás naciones del mundo. Las personas de origen extranjero representan el $12 \%$ de todo el segmento de personal calificado en el mercado laboral estadounidense. No obstante, esta proporción es similar en los países de la OCDE. De ahí que, en simples cifras, la contribución del mundo en desarrollo al desarrollado es relativamente marginal, aun cuando es estratégicamente importante dado que alivia las limitaciones del mercado laboral en los países de destino.

Para los países en desarrollo y algunos en transformación, el volumen de las habilidades involucradas es considerable. Lo que constituye una pequeña proporción del personal, en el norte, es una muy grande para el sur. Por ejemplo, cerca de un tercio de los investigadores e ingenieros que salen de los países en desarrollo trabajan en países de la OCDE. En general, los países en transformación tienen más posibilidades de negociación y pueden atraer de regreso a los intelectuales. Un ejemplo es la República Popular China. Además, una proporción cada vez menor de estudiantes chinos se traslada al exterior para estudiar (Meyer, 2005). En términos globales, es cada vez mayor la evidencia en el sentido de comunidades epistémicas, de académicos y expertos, que también hacen contactos con el país de origen (Barré et al., 2003; Meyer y Charum, 1995). Obviamente, observamos una complementariedad entre la comunidad, por un lado, y el mercado así como el Estado, por el otro, en el caso de la ganancia de cerebros; mientras que existe una incompatibilidad tanto en el caso de la fuga de cerebros, como en la pérdida de personal al cuidado de la salud en los países menos desarrollados.

Es interesante hacer notar que existen límites muy claros al patrocinio del Estado y al control jerárquico de las comunidades epistémicas. En la actualidad, están documentadas unas 40 redes de ese tipo en el mundo, en las que se incluyen miembros de 35 países en desarrollo. Dichas redes establecen actividades tales como proyectos de investigación conjuntos, intercambio de información, transferencia de tecnología, iniciativas vinculadas, sesiones de entrenamiento. Muchas de esas comunidades epistémicas se fundamentan en la idea de que el retorno no es la única alternativa al éxodo de capacidades. En cambio, existe una opción transnacional. No sólo los gobiernos nacionales, sino también las organizaciones internacionales están involucrados en el establecimiento de esas redes. Los programas de políticas existentes incluyen el llamado Transferencia de Conocimiento a través de Nacionales Expatriados, implementado por la onU. Se ocupa de la producción de bases de datos acerca de los nacionales capacitados en el extranjero, quienes podrían estar dispuestos a participar en proyectos de desarrollo específicos. También existe el programa Migración para el Desarrollo en África, de la Organización 
Internacional para las Migraciones (OIM) que busca movilizar las habilidades de los originarios de naciones africanas para el beneficio del desarrollo de África. No obstante, la emigración de quienes están altamente capacitados sólo es positiva si existe una reserva mínima de personas igualmente calificadas. De otro modo, no existe una capacidad de reemplazo. Un síntoma es que cerca de 250 mil profesionistas, nacidos en África, trabajan fuera del continente y cien mil profesionistas no africanos, que están en África, son empleados por las agencias de la onU con el patrocinio de ONG. Mientras que los sistemas de entrenamiento e investigación se organizan, principalmente, siguiendo las líneas nacionales, las comunidades epistémicas evaden, con frecuencia, los estrechos principios del «interés nacional». Un caso de importancia, que resulta relevante, es la red denominada Red Caldas, establecida por el gobierno de Colombia a principios de la década de los noventa (Chaparro et al., 2004); esta experiencia da una noción de la importancia de las comunidades de investigación especializadas, construidas siguiendo la lógica de redes descentralizadas, las que cuentan con una genuina orientación transnacional. El gobierno estableció redes radiales descentralizadas, que más tarde se desarrollaron para dar lugar a comunidades epistémicas con un carácter descentralizado. Este proyecto se desenvolvió a partir de nodos nacionales en los noventa. El gobierno estableció nodos nacionales en todos los países del mundo que tuvieran una masa crítica de estudiantes e investigadores colombianos de posgrado; en total fueron 27 países con 874 investigadores y estudiantes de posgrado. Se formaron grupos de trabajo en los que se reunió a investigadores que se encontraban en Colombia, investigadores colombianos que residían en diversos países e investigadores de países desarrollados interesados en esos tópicos. La Red Caldas realizó un registro de tales proyectos. En la segunda mitad de la década de los noventa resultó claro que los investigadores con residencia en Colombia y quienes estaban en el extranjero no se reunían en torno a nodos nacionales, sino que coincidían en comunidades epistémicas especializadas. De la misma manera, Red Caldas evolucionó en una «red de redes» cuando disminuyó el apoyo del centro, es decir, del gobierno. Los nodos nacionales, prácticamente, desparecieron a fines de los noventa. Las comunidades epistémicas, en las que realmente participaban los investigadores relacionados con Colombia, contaban con una membresía y una actividad mucho más claramente definidas, a la vez que se caracterizaban por un modelo más participativo y menos jerárquico. En síntesis, fracasó el esfuerzo centrado en la gestión del Estado por establecer comunidades epistémicas transnacionales, siguiendo líneas nacionales, mientras que las redes descentralizadas tuvieron éxito al atraer a científicos de las disciplinas naturales y sociales.

Las comunidades epistémicas y los flujos asociados de conocimiento proporcionan un ejemplo excelente de los diferentes principios para la provisión de bienes en las comunidades, mercados y Estados. Las comunidades proporcionan bienes del tipo de los clubes, que han de diferenciarse de los bienes públicos y privados. Mientras que los bienes públicos -y por tanto, el bien común propor- 
cionado por los Estados de manera tipo ideal - se caracterizan por los principios asociados de no exclusión y acceso para todos, es decir, que no hay exclusividad, los bienes privados se encuentran en el otro extremo. Los bienes tipo club se sitúan entre esos extremos, en el sentido de que los no miembros de hecho pueden quedar excluidos. Sin embargo, con fundamento en la membresía, los bienes que se proporcionan son efectivamente colectivos (Breuer, Faist y Jordan, 1995). En pocas palabras, lo que más importa en la provisión de bienes del tipo club son los límites entre los miembros y los no miembros. En el caso de las comunidades epistémicas, el conocimiento es equiparable a bienes de club, lo que sitúa al conocimiento entre un bien público y un bien privado. Por una parte, los crecientes flujos de conocimiento, por encima de las fronteras, han contribuido al rápido esparcimiento y adopción de tecnologías informativas y de comunicación, lo que sugiere que el conocimiento puede considerarse un bien público. Para los actores nacionales, internacionales y transnacionales involucrados en el desarrollo, el conocimiento es un bien público global. Por otro lado, el conocimiento es un bien privado, lo que se refleja en la importancia de los derechos de propiedad industrial (DPI) y de otras formas de apropiación del conocimiento. Obviamente, la producción y el acceso al conocimiento son selectivos. Las comunidades epistémicas transnacionales proporcionan mecanismos para la traducción de la ciencia en conocimiento, como un factor de producción y toma de decisiones. Ciertas formas de conocimiento se generan a través de comunidades de personas con ideas similares, o de colegas que trabajan en un cierto campo o dentro de un tema concreto. Las comunidades epistémicas también están conectadas con trabajadores dedicados a la extensión y con los usuarios finales (llamados accionistas). En síntesis, las comunidades epistémicas son formas organizacionales para producir y acceder al «conocimiento protegido» que circula libremente sólo dentro de estas comunidades y que es accesible, en exclusiva, para los miembros. Quienes pertenecen a esas comunidades ocupan, así, la función de "grupos estratégicos» (Evers y Schiel, 1988) que generan el conocimiento como bien público y como bien privado.

\section{Ideas e intereses políticos:}

\section{comunidades étnico-nacionales}

La tercera forma de transferencia de capital se relaciona con las más visibles amenazas a la compatibilidad de las comunidades transnacionales y los Estados, es decir, el capital político-cultural intercambiado en las comunidades étnico-nacionales. Tres categorías de comunidades transnacionales también apuntan hacia tres grados de desafíos potenciales al llamado terruño (homeland), país de origen o país de emigración: los refugiados/exilados, las diásporas carentes de Estado y las diásporas con base estatal. El papel de las tres categorías, claramente, se extiende más allá del flujo del capital financiero - para el financiamiento de ejércitos re- 
beldes (Collier y Hoeffler, 2000) — y apunta a la definición del meollo de los intereses e identidades de las comunidades políticas. Los Estados no sólo se basan en una infraestructura organizacional y en diversos mecanismos de establecimiento de reglas para el gobierno legítimo, así como de la puesta en práctica de la instrumentación de estas reglas, sino también en los elementos comunes de identidad que subyacen a las comunidades políticas, como son las naciones. Los refugiados, los emigrados y los miembros de las diásporas carentes de Estado, a primera vista, parecerían desafiar o incluso competir con los países de emigración existentes. Hay diversas formas de transferir el capital político-cultural, las cuales van desde las actividades de los emigrados hacia el mejoramiento de los derechos humanos, en sus países de origen, hasta el nacionalismo a distancia, que intenta formar un nuevo Estado-nación. El nacionalismo a distancia, en particular, puede rastrearse a los primeros años del Estado-nación. Uno de sus críticos, Lord Acton, llamó a las diásporas «el semillero de la nacionalidad».

Con mucha frecuencia, los refugiados y exiliados han tenido un impacto en el desarrollo político, cuando median entre grupos en competencia o proporcionan recursos para la reconciliación y la reconstrucción. Los ejemplos destacados incluyen el papel de la diáspora sudafricana en el movimiento de oposición al Apartheid, así como la más reciente participación de las diásporas de Uganda y Nigeria. La retórica en torno a esos esfuerzos ha sido el buen gobierno y el régimen de la ley, la puesta en práctica de los derechos humanos y la democratización. Igualmente importantes han sido las comunidades de refugiados y exiliados que, desde el extranjero, han desatado conflictos en los países de origen, entre ellos los albano-kosovares (Hockenos, 2003), los mujaidines, en el caso de Irán, o los rebeldes chechenios. Un grado mayor de coherencia político-cultural puede encontrarse entre las diásporas "carentes de Estado», que tienen la intención explícita de fundar un nuevo Estado-nación o, al menos, lograr un mayor grado de autonomía en el territorio declarado como nación. Esas comunidades son representadas por organizaciones o movimientos de liberación que están en abierto conflicto con la antigua nación, como atestiguan los casos de las comunidades kurda y tamil.

A primera vista, un grado más alto de complementariedad se da en el caso de las diásporas establecidas y «basadas en un Estado», como sucede con las diásporas armenia, china y palestina, en Estados Unidos así como en Europa. Algunas veces, estas diásporas establecidas son consideradas, por Orión, como recursos estratégicos, como sucede con la visión del gobierno de China de los «chinos en el extranjero» poseedores de altas calificaciones. La noción de que el país de origen y la diáspora constituyen un sólo pueblo es, de manera especial, fuerte entre aquellos relativamente débiles, nuevos o reconstituidos, en conflicto con otros países o grupos, como los armenios-azeri (Shain, 2002). Se podría argumentar que las diásporas nacionales, que participan en los asuntos exteriores de un país receptor, pasan de ser grupos carentes de derechos a ser poseedores de un boleto de entrada en la principal corriente de la sociedad y la política (sobre la política exterior de 
Estados Unidos, véase Shain, 1999). Empero, las diásporas fuertes y los Estados con escasa experiencia producen una compleja situación de política internacional y transnacional, que va más allá de la noción de «juegos de dos niveles» (Putnam, 1988). El concepto de juegos de dos niveles considera tanto las demandas mínimas de los actores políticos dentro de la nación, como las de sus contrapartes. La intervención de las diásporas fuertes implica una extensión hacia un juego de tres niveles, en especial en la perpetuación y resolución del conflicto. Además, las diásporas establecidas pueden jugar un papel crucial en la definición del interés e identidad nacionales. Tanto las identidades como los intereses colectivos, indudablemente, son constructores dinámicos y flexibles. Los intereses de la diáspora y del país de origen pueden divergir de manera significativa y no constituyen un todo unificado. Las formas de la identidad transnacional pueden conectar a los países de origen con los de destino. Existen instancias de identidades transnacionales de tipo nacionalista, como en el caso de Polonia e Irlanda y sus diásporas en Estados Unidos, formadas en el siglo xIX y principios del siglo XX. En casos excepcionales, algunas interpretaciones de la identidad transnacional pueden separarse de la identidad nacional y competir, así, con el transnacionalismo estatista, como en la idea de una diáspora judía que no se centre en el Estado israelí, sino en una diáspora transnacional o incluso global (Boyarin, 1994).

Todo ello sugiere que una perspectiva transnacional, en torno a los intereses y las identidades nacionales, puede apoyar, competir e, incluso, presentar un desafío a la congruencia de un pueblo, un territorio y una autoridad en un Estado. Uno de los desafíos va más allá de esta trinidad. Si las comunidades transnacionales se conciben a sí mismas como diásporas conectadas con un proyecto de construcción de nación, como los albano-kosovares a fines de los años noventa, por lo general se representan a sí mismos como entidades étnicamente homogéneas; en pocas palabras, un Volk que se basa en una herencia cultural común y no tanto en las predisposiciones subjetivas de sus ciudadanos respecto a un Estado y una constitución. Existe una tensión inherente entre el concepto de Estado que se define, por un lado, por las diásporas nacionalistas según el cual los miembros constituyen un Volk y, por el otro, un concepto democrático que percibe a la comunidad política compuesta por todos sus ciudadanos.

\section{PERSPECTIVA: LOS ESPACIOS SOCIALES}

TRANSNACIONALES Y LOS ESTADOS

Este análisis ha intentado sugerir algunas de las formas en que las comunidades desempeñan un papel en la transnacionalización y el desarrollo, al señalar la interacción con otros principios del orden social, en especial, el mercado y el Estado. Las unidades a las que se hace referencia con el término comunidad y los propios espacios colectivos transnacionales están bajo constante reconstrucción. 
Además, la cambiante relación y la línea de demarcación entre mercado, Estado y comunidad es, en sí misma, producto de unas políticas públicas contenciosas (Stratton y Orchard, 1994). En la investigación futura habrán de considerarse dos temas: i) la reconstrucción de los grupos, asociaciones, redes y organizaciones transnacionales; ii) el cambiante papel de la manera en que los Estados abren y restringen los espacios sociales. El primer tema ayuda a evitar la esencialización de los sujetos transnacionales y a contrarrestar la tendencia, tanto de la investigación académica como del diseño de políticas, a reconstruir a los sujetos colectivos transnacionales como actores unitarios. El segundo es necesario para clarificar el mudable papel de los Estados. Habrá que prestar más atención a la manera en que los Estados estructuran los espacios sociales transnacionales, por ejemplo, a través de la regulación de la migración transnacional. ${ }^{7}$

Como sugieren los ejemplos empíricos discutidos, los colectivos trasnacionales, como grupos, asociaciones, organizaciones y diásporas, no pueden tratarse como actores unitarios, si lo que se desea es comprender las tensiones inherentes a los espacios trasnacionales y las implicaciones para la concepción de la transnacionalización. Sin duda alguna, con el proceso de globalización se han modificado las oportunidades para los actores transnacionales, no sólo para las colectividades basadas en los migrantes (Evans, 2000). Gracias al aparente incremento en la interconexión a larga distancia, las facilidades de la comunicación cara a cara y la interacción que permiten los viajes así como la difusión de las ideas y el conocimiento, la vida social que atraviesa las fronteras estatales se ha tornado más densa y amplia. Los espacios entre los Estados se han multiplicado. Algunos de los más preciados conceptos del estudio de la migración deben ponerse en duda porque, quizá, ya no sean los más adecuados para captar, de manera más fluida, los estilos de vida, los modos de acción y el comportamiento colectivo. Las vidas de los migrantes no necesariamente se caracterizan por un establecimiento único y un sólo compromiso con una sociedad o un conjunto de asociaciones o de grupos sociales. Por lo tanto, las distinciones dicotómicas, como «origen» frente a "destino», «emigración» frente a «inmigración» ya no se sostienen más, aunque sea porque muchos de los países tradicionales de emigración se han convertido en países, a la vez, de tránsito y de inmigración, con el caso de Turquía como un ejemplo típico. Otras dicotomías menos obvias, como temporal frente a permanente o migrante laboral frente a refugiado, tampoco se sostienen si de lo que se trata es de hacer una cartografía de las poblaciones en movimiento. Un primer paso ha sido el renovado interés en la noción de espacio social. Ello ha implicado, entre otras cosas, concebir a la migración, más allá de su construcción demográfica, como «flujos» o «reservas» de personas y examinar los «lugares intermedios». Este tren de reflexión

7 Para un análisis de cómo los procesos del mercado interactúan con la migración, en el caso de dos economías fuertemente entrelazadas, véase Delgado Wise y Márquez Covarrubias (2005). 
no habría de limitarse ante otras nociones importantes, como la de ciudadanía. Es claro que los espacios sociales transnacionales no forzosamente implican que las comunidades de origen y las comunidades de destino sean congruentes, en términos de sus intereses e ideas. Como se mencionó antes, los actores transnacionales que no residen, de manera permanente, en la comunidad de origen pueden tener nociones muy diferentes de desarrollo, en comparación con los que están en el terruño. Este problema de incongruencia no ha recibido la suficiente atención, en términos de sus implicaciones conceptuales. Por ejemplo, nociones como la de ciudadanía transnacional se utilizan para describir la participación, derechos, pertenencia y deberes políticos de los migrantes transnacionales por medio de mecanismos como las asociaciones de oriundos. Sin embargo, un elemento importante de la ciudadanía es una equitativa libertad política, el principio de la democracia. Este principio sostiene que quienes toman las decisiones (voz) no deberían tener la necesidad de salir voluntariamente. Mientras que es probable que todavía quisiéramos utilizar el término ciudadanía en un contexto transnacional, querríamos evitar la falacia de, simplemente, transponer conceptos del nivel del Estado-nación a los espacios sociales transnacionales.

No obstante, el concepto de Estado-nación tiene un importante papel en la definición de las estructuras de oportunidad, en los espacios sociales y las transacciones transnacionales relacionadas con el desarrollo. Muy al contrario de las suposiciones acerca del detrimento del principio del Estado frente al mercado y la comunidad, los Estados desempeñan un papel activo para configurar las condiciones mismas de los sujetos transnacionales que participan en los temas del desarrollo. La relación de la comunidad, con lo que se denomina globalización, se hace aún más evidente en los esfuerzos de los gobiernos nacionales por modificar las políticas de inmigración. A diferencia de las políticas públicas de los años sesenta, no sólo se centran en la migración de retorno, como forma de desarrollo, sino también en el patrocinio de las redes transnacionales. Los diseñadores de políticas en los Estados de bienestar avanzados —y en los países de la OCDE— han relacionado a la inmigración con el futuro de las provisiones sociales. Al enfrentar una transición de magnitud considerable, una línea de razonamiento percibe, a la inmigración, como un aporte al rejuvenecimiento de los mercados de trabajo, a la conservación del tamaño de la población — para asegurar el crecimiento económico futuro y para suavizar la transición a otras formas de plantear los esquemas para las pensiones en la edad avanzada y para rejuvenecer los mercados laborales-. En pocas palabras, el tema de la migración de reemplazo (DPNU, 2000) ha ascendido, en la escala de los instrumentos de política, en la actual reestructuración de los Estados de bienestar. Una de las justificaciones para utilizar la inmigración con propósitos económicos, y por tanto definir con claridad el «interés nacional» en los países europeos, es el esfuerzo por modificar los efectos de la migración internacional en los países en desarrollo. Esta tendencia se hace más visible que nunca en el tema de los migrantes con una escolaridad de tercer nivel. 
La política contemporánea de inmigración en el mundo de la OCDE, como hemos visto, en parte se preocupa por la competencia para obtener los mejores cerebros del planeta, no sólo por atraer a trabajadores altamente calificados como colonos, permanentes o temporales, en sectores como la tecnología de la información, sino también como estudiantes internacionales. Esta inversión en conocimiento se concibe como una ayuda para lidiar con las tormentas de la competencia económica global, así como con la creciente competencia entre las instituciones de educación superior y de investigación (Bericht der Unabhängigen Kommission Zuwanderung, 2001). Cada vez más, a la evidente crítica de la fuga de cerebros, se contraponen las referencias a las recompensas reales y potenciales de la ganancia de cerebros. Los gobiernos francés y británico, por ejemplo, han racionalizado el reclutamiento selectivo de expertos altamente calificados, al introducir esquemas de desarrollo cooperativo (House of Commons, 2004). Esas tendencias se manifiestan no sólo en la dimensión económica del orden social, sino también en el ámbito político. Las nuevas constelaciones políticas internacionales que siguieron a la caída del bloque socialista, la difusión a largo plazo de los derechos humanos, la democracia como metadicurso normativo y la rampante implosión del orden político, en algunas partes del mundo en desarrollo, han conducido a una creciente cifra de intervenciones armadas, como las acciones justificadas con bases humanitarias u operaciones para contrarrestar el terrorismo. Las potencias occidentales han intervenido para poner fin a conflictos fuera del mundo de la OCDE, al tiempo que han participado en esfuerzos de reconstrucción posteriores a los conflictos bélicos, en una gran y creciente escala. Estos esfuerzos requieren de un ejército de expertos para construir los rudimentos del régimen de derecho, a veces desde cero, por ejemplo en Afganistán. Una de las cuestiones administrativas más cruciales ha sido la selección del personal para esas empresas. Todavía está vigente el debate acerca de situar a refugiados y exiliados de la «primera generación» que, probablemente, tengan un conocimiento de primera mano de la situación a partir de su experiencia, o de personas más jóvenes, como los hijos de migrantes, que cuenten con «antecedentes migratorios» y que no estén involucrados personalmente (von Carlowitz, 2004).

Estas consideraciones, en torno al papel de los Estados, ya sugieren que el cambiante papel del Estado, en la reflexión de las políticas de desarrollo y las políticas reales, no sólo ha de restringirse a su papel de conservar las fronteras, es decir, las tareas de infraestructura para los mercados. En contraste, los Estados desempeñan, de manera mucho más activa, un papel en la política de desarrollo más allá de proporcionar las condiciones macroeconómicas. Por ejemplo, las políticas de control fronterizo de los países de inmigración están, íntimamente, relacionadas con permitir y restringir la movilidad de personas con el potencial de los grupos y las asociaciones transnacionales. La Unión Europea (UE) dio un giro a sus políticas, de luchar contra las «causas de raíz» a la ayuda al desarrollo (European Comisión, 2002). En la cumbre europea de Sevilla, en 2002, los líderes 
de los Estados miembros acordaron que toda asociación o acuerdo de cooperación, que establezca la UE/CE con cualquier país, ha de incluir una cláusula sobre el manejo conjunto de los flujos migratorios y la obligación de admitir a los que regresan, en el caso de inmigración ilegal. No obstante, el esfuerzo de la UE, por vincular el control de la migración con la ayuda externa, de alguna manera tiene sus inclinaciones a favor del control. La mayor proporción del presupuesto fue designada al "manejo de los flujos migratorios», es decir, al fortalecimiento de la vigilancia fronteriza y a la mitigación de la migración ilegal o irregular. Todavía más explícitos son los contratos bilaterales entre los países de inmigración y emigración, que se basan en que los países de emigración están dispuestos a aceptar, de regreso, a los solicitantes de asilo que sean rechazados y a vigilar la migración indocumentada. El esfuerzo fue encabezado por Italia, al ofrecer permisos temporales de trabajo y ayuda oficial para el desarrollo a los países abiertos a ellos, como Albania y Túnez. Es de hacer notar que la UE y su litoral en el Mediterráneo puede constituir un caso especial que no se compara con otras formas de organización supranacional, porque la UE se ha comprometido con una lógica de expansión que implica un aumento en las funciones de vigilancia fronteriza para un conjunto de países junto a las fronteras actuales de la UE, vinculadas, hasta el momento, con la perspectiva de unirse en el largo plazo con la UE. Es de la mayor importancia no sólo considerar las políticas de desarrollo de participación directa, sino también los mecanismos indirectos y poderosos, como la manera en que los Estados estructuran sus controles fronterizos y, por tanto, los límites internos de los Estados. Dentro de estos espacios de oportunidad, surgen los espacios sociales transnacionales, que son poblados por los grupos y asociaciones transnacionales.

BIBLIOGRAFÍA

Appleyard, Reginald (ed.) (1999), Migration and Development, Nueva York, United Nations.

BMz, Bundesministerium für Wirtschaftliche Zusammenarbeit und Entwicklung (2001), Wissenschaftsförderung, Hochschulkooperation und Migrationspolitik in der Entwicklungszusammenarbeit: Neue Herausforderungen und Schwerpunkte, Stellungnahme des Wissenschaftlichen Beirats Beim BMz, no. 35.

Banco mundial (1999), World Development Report 1998-99: Knowledge for Development, Nueva York, Oxford University Press.

Barré, Philippe, Victor Hernandez, Jean-Baptiste Meyer, Dominique Vinck (eds.) (2003), Diasporas scientifiques, Expertise collégiale, Institut de Recherche sur le Développement, París, Ministère des Affaires Etrangères.

BASCH, Linda, Nina Glick Schiller y Cristina Szanton Blanc (1994), Nations Unbound. Transnational Projects, Postcolonial Predicaments, and Deterritorialized Nation-States, Langhorne, PA, Gordon and Breach. 
Bates, Robert H. (ed.) (1988), Toward a Political Economy of Development: A Rational Choice Perspective, Berkeley, CA, University of California Press.

BERICHT der Unabhängigen Kommission Zuwanderung (2001), Zuwanderung gestalten-Integration fördern, Berlín, Zeitbild Verlag.

BhagWati, Jagdish (2003), «Borders Beyond Control», en Foreign Affairs, 82, 1, pp. 98-105.

BiaO, Xiang (2005), Promoting Knowledge Exchange through Diaspora Networks, Oxford, ESRC Centre on Migration Policy and Society (COMPAS).

BoYARIN, Jonathan (1994), Remapping Memory: The Politics of Timespace, Minneapolis, University of Minnesota Press.

Breuer, Michael, Thomas Faist, Bill Jordan (1995), "Collective Action, Migration and Welfare States», en International Sociology, 10, 4, pp. 369-386.

Chang, Ha-Joon (2002), Kicking Away the Ladder. Development Strategy in Historical Perspective, Londres, Anthem Press.

Chang, Ha-Joon e Ilene Grabel (2002), Reclaiming Development: An Alternative Economic Policy Manual, Dhaka, University Press.

Chaparro, Fernando, Hernán Jaramillo y Vladimir Quintero (2004), Role of Diaspora in facilitating Participation in global Knowledge Networks: Lessons of Red Caldas in Colombia, Report prepared for the Knowledge for Development Program of the World Bank, Bogotá, diciembre 2004.

Collier, Paul y Anke Hoeffler (2000), Greed and Grievance in Civil War, Policy Research Working Papers, The World Bank, Washington, D.C., mayo 2000.

Cornelius, Wayne A., Thomas J. Espenshade, Idean Salehyan (eds.) (2001), The International Migration of the Highly Skilled: Demand, Supply, and Development Consequences in Sending and Receiving Countries, La Jolla, CA, Center for Comparative Immigration Studies, University of California, San Diego.

Dannecker, Petra (2004), "Transnational Migration and the Transformation of Gender Relations: The Case of Bangladeshi Labour Migrants», en Current Sociology 53, 4, pp. 655-674.

Delgado Wise, Raúl y Humberto Márquez Covarrubias (2005), The Reshaping of Mexican Labor Exports under NAFTA: Paradoxes and Challenges, Zacatecas, Unidad de Posgrado en Estudios del Desarrollo, Universidad Autónoma de Zacatecas.

Diamond, Larry (1996), "Is the Third Wave Over?», en Journal of Democracy 7, 3, pp. 20-37.

Escobar, Arturo (1995), Encountering Development: The Making and Unmaking of the Third World, Princeton, Princeton University Press.

European commision (2002), Integrating Migration Issues in the European Union's Relations with Third Countries, COM (2002) 703 final, diciembre 2002, Bruselas.

Evans, Peter (1996), "Government action, social capital and development: Creating synergy across the public private divide, Special section», en World Development, 26, 4, pp. 1033-1132. 
Evans, Peter (2000), «Fighting Marginalization with Transnational Networks: Counter-Hegemonic Globalization», en Contemporary Sociology, 29, 1, pp. 230-241.

Evers, Hans-Dieter y Tilman Schiel (1988), Strategische Gruppen. Vergleichende Studien zu Staat, Bürokratie und Klassenbildung in der Dritten Welt, Berlín, Reimer.

FAIst, Thomas (2000), The Volume and Dynamics of International Migration and Transnational Social Spaces, Oxford, Oxford University Press. (2003), Protecting Domestic vs. Foreign Workers: The German Experience during the 1990s, Bielefeld, Center on Migration, Citizenship and Development (COMCAD), Working Paper 1/2003.

(2004), «Towards a Political Sociology of Transnationalism: The State of the Art in Migration Research", en European Journal of Sociology, 45, 3, pp. $19-54$.

ETTE, Andreas, Thomas Faist y Mechtild Baumann (2006), The Europeanization of National Immigration Policies, Londres, Palgrave Macmillan.

Findlay, Allan M. (2003), "Skilled Transients: The Invisible Phenomenon?», en Robin Cohen (ed.), The Cambridge Survey of World Migration, Cambridge, Cambridge University Press, pp. 515-523.

Fischer, Peter A., Reiner Martin y Thomas Straubhaar (1997), "Should I Stay or Should I Go?», en Tomas Hammar, Grete Brochmann, Kristof Tamas y Thomas Faist (eds.), International Migration, Immobility and Development: Multidisciplinary Perspectives, Oxford, Berg, pp. 49-90.

Galbraith, John Kenneth (1962), Economic Development in Perspective, Cambridge, MA, Harvard University Press.

GoldRING, Luin (2002), «The Mexican State and Transmigrant Organizations: Negotiating the Boundaries of Membership and Participation", en Latin American Research Review, 17, pp. 55-99.

Guarnizo, Luis Eduardo (2003), "The Economics of Transnational Living», en International Migration Review, 37, 3, pp. 666-699.

Hamilton, Bob y John Whaley (1984), «Efficiency and Distributional Implications of Global Restrictions on Labour Mobility», en Journal of Development Economics, 14, pp. 61-75.

Hirschman, Albert (1958), The Strategy of Economic Development, Nueva Haven, CT, Yale University Press.

Hirschman, Albert (1970), Exit, Voice, and Loyalty, Harvard, MA, Harvard University Press.

Hockenos, Paul (2003), Homeland Calling: Exile, Patriotism and the Balkan Wars, Ithaca, NY, Cornell University Press.

House of commons, International Development Committee (2004), Migration and Development: How to Make Migration Work for Poverty Reduction, Sixth Report of Session 2003-04, volumen 1, Londres, The Stationary Office Limited. 
Hugo, Graeme (2003), Migration and Development: A Perspective from Asia, Iom Migration Research Series no. 14, Ginebra, International Organization for Migration (IOM).

Huntington, Samuel (1966), Political Order in Changing Societies, Nueva Haven, $\mathrm{CT}$, Yale University Press.

Kapur, Devesh (2004), Remittances: The New Development Mantra?, G-24 Discussion Paper Series, no. 29.

LevitT, Peggy y Ninna Nyberg-Sorensen (2004), The Transnational Turn in Migration Studies, Ginebra, Global Commission on International Migration (GCIM), Global Migration Perspectives, no. 6.

Mahler, Sarah J. y Patricia R. Pessar (2001), "Gendered Geographies of Power: Analyzing Gender Across Transnational Spaces», en Identities: Global Studies in Culture and Power 7, 4, pp. 441-459.

Martin, Philip L. (2004), Migration and Development: Toward sustainable Solutions, International Institute for Labour Studies, Discussion Paper no. 153, Ginebra, ILO.

Mcmichael, Philip (1996), Development and Social Change, Thousand Oaks, CA, Pine Forge.

Mellyn, Karen (2003), Worker Remittances as a Development Tool: Opportunities for the Philippines, Asian Development Bank.

Meyer, Jean-Baptiste y Jorge Charum (1995) «La fuite des cerveaux' est-elle épuisée?», en Cahiers des Sciences Humaines, 31, 4, pp. 1003-1017.

Meyer, Jean-Baptiste (2005), "Contribution to Conference on Linking Migration and Development: Implications for Policy», en Forum: Développement (Neuchâtel), pp. 13-17.

Naciones Unidas, Department of Economic and Social Affairs (2004), World Economic and Social Survey. Part II: International Migration, Nueva York.

Population Division (2000), Replacement Migration-Is it a Solution to Declining and Aging Populations?, Population Division, Department of Economic and Social Affairs, Un. ESA/ P/ wr.160, 21 de marzo de 2000, Nueva York.

North, Douglass C. (1990), Institutional Change and Economic Performance, Cambridge, Cambridge University Press.

NyberG-Sørensen, Nina, Nicolas Van Hear y Poul Engberg-Pedersen (2002), «The Migration-Development Nexus: Evidence and Policy Options: A State-ofthe-Art Overview», en International Migration 40, 5, pp. 3-48.

Orozco, Manuel (2002), Attracting Remittances: Market, Money and Reduced Costs, Report commissioned by the Multilateral Investment Fund of the InterAmerican Development Bank, Washington, D.C.

PAGE, John y Richard Adams (2004), The Impact of International Migration and Remittances on Poverty, Washington, D.C., Banco Mundial.

Putnam, Robert D. (1988), «Diplomatic and Domestic Politics: The Logic of TwoLevel Games», en International Organization, 41, 3, pp. 427-461. 
Rauch, James (2001), «Business and Social Networks in International Trade», en Journal of Economic Literature, 34, pp. 1177-1204.

Rodriguez, Robyn M. (2002), "Migrant Heroes: Nationalism, Citizenship and the Politics of Filipino Migrant Labor», en Citizenship Studies, 6, 3, pp. 342-356. SengHAAS, Dieter (ed.) (1974), Peripherer Kapitalismus: Analysen über Abhängigkeit und Unterentwicklung, Frankfurt del Meno, Suhrkamp.

SHAin, Yossi (1999), Marketing the American Creed Abroad, Cambridge, Cambridge University Press. (2002), "The Role of Diasporas in Conflict Perpetuation or Resolution», en SAIS Review, 22, 2, pp. 115-144.

SHAIN, Yossi y Aharon Barth (2003), "Diasporas and International Relations Theory", en International Organization, 57, 3, pp. 449-479.

Sinn, Hans-Werner (2004), Migration, Social Standards and Replacement Incomes, CESIFO Working Paper no. 1265, Munich, Ludwig-Maximilians-Universität.

SoYsal, Yasemin N. (1994), The Limits of Citizenship, Chicago, University of Chicago Press.

StARK, Oded y Y. Wang (2001), Inducing Human Capital Formation: Migration as a Substitute for Subsidies, Economics Series, no. 100, Viena, Institute for Advanced Studies.

STALKen, Peter (1994), Workers without Frontiers: The Impact of Globalization on International Migration, Boulder, co, Lynne Rienner.

SteHr, Nico (1992), The Culture and Power of Knowledge: Inquiries into Contemporary Societies, Berlín, De Gruyter.

Streeck, Wolfgang y Philippe C. Schmitter (1985), "Community, Market, Stateand Associations? The Prospective Contribution of Interest Governance to Social Order», en European Sociological Review, 1, 2, pp. 119-138.

Stretton, Hugh y Lion Orchard (1994), Public Goods, Public Enterprise, Public Choice: Theoretical Foundations of the Contemporary Attack on Government, Londres, St. Martin's Press.

TsenG, Yen-Fen (2000), "The Mobility of Entrepreneurs and Capital: Taiwanese Capital-Linked Migration», en International Migration, 38, 2, pp. 143-166.

Van Hear, Nicolas (2003), «Refugee Diasporas, Remittances, Development, and Conflict», en Migration Information Source, primero de junio de 2003, Washington, D.C., Migration Policy Institute.

Von Carlowitz, Leopold (2004), «Migranten als Garanten? Über die Schwierigkeiten beim Rechtsstaatsexport in Nachkriegsgesellschaften", en HSFK Standpunkte, nr. 6/2004, Frankfurt.

Weiner, Myron (1986), «Labour Migrations as Incipient Diasporas», en Gabriel Sheffer (ed.), Modern Diasporas in International Politics, Londres, Croom Helm, pp. 47-74. 